\title{
Editorial
}

\section{Human and environmental rights, protection of biological diversity, and marine spatial planning in the Asia Pacific region}

\section{APJEL IN THE ASIA PACIFIC REGION}

This is the second issue of APJEL in the 2019 volume, and it features a contribution on environmental rights in Asia and the Asia Pacific along with articles on key subjects relevant to development and environmental law and governance in Bangladesh, China and Thailand, Maldives, and New Zealand. The five articles in this issue join the eight in the first issue of 2019, which addressed a number of Asian and Pacific jurisdictions including Australia, Bangladesh and China, Indonesia, and Papua New Guinea. It has been pleasing to see the growing scholarly interest in environmental law and policy developments in a growing range of countries in the region.

We welcome both submissions of general environmental relevance and submissions on specific, focused issues, as long as both are of relevance to Asian Pacific scholarship. APJEL's goal remains the publication of careful research on a broad range of environmental law issues across the Asia Pacific, drawing lessons from comparisons and contrasts with and between countries facing similar realities, constraints, and opportunities. At the same time, it is through in-depth analysis of specific environmental law developments in specific jurisdictions that true comparative understanding can be developed and enriched, and the articles in the present issue illustrate ways in which environmental protection can be enhanced by considering quite particular problems.

\section{THE ENVIRONMENTAL SITUATION IN THE ASIA PACIFIC}

A recent regional assessment report published by the Intergovernmental SciencePolicy Platform on Biodiversity and Ecosystem Services (IPBES) ${ }^{1}$ provides an excellent 'snapshot' of the current state of natural ecosystems in the Asia Pacific, and the situations of people who rely on such resources. ${ }^{2}$

Key messages outlined include that nature makes an important contribution to human well-being and good quality of life in a region characterized by one of the fastest urbanization rates and with concomitant rapid expansion of agricultural land; with the largest number (400 million of 767 million) of people living below the poverty line; and a range of diverse values and value systems supported by rich biodiversity levels. ${ }^{3}$

The region is highly diverse and there are varying trends, and underlying drivers thereof, identifiable in respect of biodiversity and ecosystem services. There are

1. See, generally, www.ipbes.net/.

2. IPBES, 'Assessment Report on Biodiversity and Ecosystem Services for Asia and the Pacific: Summary for Policymakers' (2018) www.ipbes.net/assessment-reports/asia-pacific.

3. Ibid, 10. 
contrasting trends in biodiversity status, with alpine ecosystems, coastal systems, forests, inland freshwater systems, and wetlands being the most threatened, despite increases in forest cover in certain regions. ${ }^{4}$ Other trends identifiable include declines in populations of large wild mammals and in bird populations, with such declines having significant consequent impacts on ecosystems. ${ }^{5}$ Further problems include growing numbers of alien invasive species, which have impacts on coastlines and islands especially; lack of correlation between increased protected area coverage and coverage of the areas which most need protection; the decline of traditional agrobiodiversity in the face of increasing monoculture and, concomitantly, a decline of indigenous and local knowledge; significant declines in capture fisheries in a region which depends heavily upon fish for food; critical threats to coral reefs, the health of which is 'interlinked to other coastal habitats, especially mangroves, intertidal flats and seagrass beds'; climate change impacts, including sea-level rise, and changes in species distribution, breeding and migration timing, and the frequency of outbreaks of diseases and pest species; and a dramatic rise in the production of waste as more natural resources are consumed. ${ }^{6}$

Not all is gloom. The third key message concerns the implications of declining biodiversity and opportunities to sustain nature's contribution to people, and the report indicates that stress on and risks for ecosystems are created, and livelihoods and food security for people threatened, when direct drivers (such as climate change, habitat conversion, illegal trade in wildlife, invasive alien species, pollution, and unsustainable use) combine with indirect drivers (such as demographic and socioeconomic changes). ${ }^{7}$ However, interlinkages can be altered through environmental governance and policy interventions. Further implications include the ongoing need to reduce poverty; but seen against the potential for better application of scientific knowledge and technology to reduce pressure on ecosystems and improve energy, food, and water security. ${ }^{8}$ Although not occurring fast enough, per the report, to reduce biodiversity loss, it is recorded that 'countries with high economic growth are reporting an increase in forest and protected area coverage'; and it is suggested that policy-makers can improve the situation if they account in their work for the 'complexity and dynamism of human-nature interactions', especially by 'using scenarios adapted to unique local and national characteristics'.

The fourth key message concerns governance options, institutional frameworks, and policies, and suggests that 'collaborative, participatory and decentralized governance' can help to create 'an enabling environment for mounting joint actions to improve ecosystem health by giving everyone a voice and a stake'. ${ }^{10}$ It is further suggested that there is 'great potential for driving the region towards sustainability' by mainstreaming biodiversity - meaning the integration of biodiversity conservation 'into broader areas, including poverty alleviation, climate adaptation and degraded land rehabilitation programmes' ${ }^{11}$ It is next suggested that multiple benefits can be

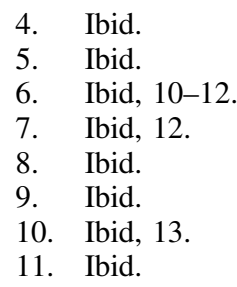


obtained from adopting ecosystem-based approaches (such as disaster risk reduction, ecosystem based adaptation, and sustainable management of forests and pastures) - with such measures also being conducive to fostering synergies between biodiversity conservation and international instruments. ${ }^{12}$ It is then suggested that positive results are being seen from various transboundary conservation initiatives; from partnerships with the private sector, with non-governmental organizations, and with individuals. ${ }^{13}$ Finally, it is suggested that it is possible for sustainable production, consumption, and waste management policies to assist in reducing biodiversity losses. ${ }^{14}$

The report is worth reading both as a sobering, extensively researched consideration of the multiple environmental complexities and problems facing the Asia Pacific region; but also for its identification of potential good practices and even solutions to environmental and related problems. Many of the issues raised in the report appear in, and are explored in more depth in, articles in APJEL.

\section{THE ARTICLES IN THIS ISSUE}

\subsection{Articles}

The first article in this issue, by Joshua C Gellers and Chris Jeffords, ${ }^{15}$ explains that human rights relating to environmental protection have spread all over the world and continue to find homes in an ever-growing list of national constitutions. The writers explain that this has been an ongoing process since the emergence of such rights in the 1970s. They categorize such rights as being 'substantive', 'procedural', or 'derivative' environmental rights, and argue that over the last two decades, the proliferation of these rights has caught the attention of legal scholars and social scientists, who have sought to catalogue their distribution and analyze the origins and impacts of this development. The literature in this area has, they explain, provided anecdotal updates concerning environmental rights jurisprudence at the national and regional levels and global quantitative assessments regarding the effects that such rights have on humans and the environment. However, they contend that there has been little empirical examination of regionally-focused variations when it comes to the presence and the impacts of such environmental rights.

Gellers and Jeffords' article makes use of statistical techniques in order to determine what, if any, correlation exists between environmental rights and environmental performance within the Asia Pacific region. They argue that preliminary results suggest that, over the past several years, countries with environmental rights have experienced strong improvements in ecosystem vitality and corresponding weak reductions in measures of environmental health. In addition, they argue, there is evidence of important intra-regional differences - with South and South-Western Asia arguably having some of the world's most innovative environmental rights jurisprudence, while North and Central Asia possess the region's greatest concentration of constitutions featuring environmental rights. The article concludes with several

12. Ibid.

13. Ibid.

14. Ibid.

15. 'Environmental rights in the Asia Pacific region: taking stock and assessing impacts'. 
recommendations for policy-makers in the region regarding the adoption and implementation of environmental rights.

The Asia Pacific region is blessed with rich biological diversity and species richness; but cursed with multifold difficulties in successful management of this wealth. The second article is by Alexandre Chitov ${ }^{16}$ and addresses one of these difficulties combatting illegal international trade in endangered species. Chitov analyzes the major international agreement in this area: the Convention on International Trade in Endangered Species of Wild Fauna and Flora, 1973 (CITES) in the particular context of two states (China and Thailand). The paper argues that CITES does not sufficiently address the need of the two states when it comes to criminalizing illegal trade in endangered animals and plants across borders. CITES requires an increased administrative control over the trade which many developing countries struggle with. Under the influence of CITES, the 'crime' of illegal trade is defined in China and Thailand narrowly as being 'trade in violation of administrative controls'.

The arguments presented are, first, that states such as China and Thailand must adopt broader concepts of the crime of illegal trade in endangered species; and, second, that there is a need to adopt this concept on an international level in order to assist successful fulfillment of such states' international obligations.

International trade is but one potential threat facing endangered species - there are many other threats. Some of these, including fishing and tourism, are considered in the third article in this issue, by Erika J Techera and Madelaine Cannell-Lunn. ${ }^{17}$ Maldives is a small island developing state in the Indian Ocean which is comprised of multiple low-lying, sandy islands and coral reefs. Its long history of human occupation has been characterized by great dependence on environmental resources, particularly those provided by the ocean, for all of food, resources, and trade. Maldives relies heavily today upon nature through tourism and fisheries; and proper conservation and sustainable use of the environment and its resources are therefore of great, arguably even paramount, importance to Maldives. In response to growing environmental pressures, including climate change, the state has engaged at global and regional levels, ratifying treaties and participating in key international institutions. It has also developed national law and policy, as well as relevant plans and strategies focused on sustainability.

However, the authors contend that, despite this activity, relatively little legal research has focused on Maldives. This article contributes to literature on Maldives by exploring environmental, fisheries, and tourism laws and policies, analyzing current legislative developments, and making tentative recommendations in areas where governance could be enhanced. This article will be helpful in understanding the challenges in other small island countries in the Asia Pacific region.

Worldwide, it is now recognized that 'pest' species, including both alien and native invasive species, pose a serious threat to the conservation of biological diversity. In the fourth article, by Nicola Wheen and Heidi Baillie, ${ }^{18}$ the problem of pest species

16. 'International law and criminalizing illegal trade in endangered species (from the Far Eastern perspective)'.

17. 'A review of environmental law in Maldives with respect to conservation, biodiversity, fisheries and tourism'.

18. 'GMOs, pests and participatory and representative democracy in decision-making about GM activities in New Zealand'. 
in New Zealand is considered. It is explained that pests, especially rats, stoats, and possums, pose a significant threat to New Zealand's endemic biodiversity.

The authors advise that a potential new means of controlling these pests is provided by genetic modification (GM). However, the authors characterize the use of GM as a 'hot' environmental problem on the basis that it has complex and controversial social, cultural, and economic dimensions in New Zealand. They explain that no genetically modified organisms (GMOs) have been released into the New Zealand environment, other than in vaccines. GM developments and field tests have been approved under the Hazardous Substances and New Organisms Act, 1996, but the responsible authority is criticized as having a science-based bias, resulting in it over-emphasizing representative rather than participatory approaches to GM regulation. Consequentially, they explain, communities opposed to GM have turned to the participating planning scheme under the Resource Management Act, 1991 to block GMO releases using rules in local policies and plans. In an effort to prevent these rules impeding the release of all GMOs in New Zealand, including GMOs in vaccines, Parliament moved to allow the Minister to veto local anti-GMO rules, except for rules about GM crops. The extent to which this amendment results in a re-assertion of representative democracy over participatory democracy in GM regulation in New Zealand depends, the authors argue, on how widely the courts interpret the Minister's new power.

No matter how much states may claim to value the sustainable management of natural resources, a reality in many states in the Asia Pacific region is that there are many competing priorities and economic drivers are often given precedence over environmental considerations, even where the financial rewards are low and the environmental harm obviously great.

In the fifth and final article in this issue, by Asraful Alam, ${ }^{19}$ it is argued that the current arrangements for the management of the marine resources of Bangladesh are not adequate for sustainable management. Marine Spatial Planning (MSP) may, according to the author, provide a tool to achieve sustainable management of marine resources. The Government of Bangladesh, it is explained, is planning for the development of MSP for sustainable management of the marine resources in the Bay of Bengal. However, the author contends that a clear understanding of the current and required legal and institutional arrangements for the development of MSP in Bangladesh is essential for sustainable management of the marine resources.

The article analyzes the current legal and institutional arrangements concerning the management of marine resources and explores potential inadequacies for the development of MSP for sustainable management. By way of comparison, the article refers to the legal and institutional arrangements of other coastal states which have already developed MSP to benefit the development of MSP in Bangladesh. Considering the geographical location of Bangladesh within the Bay of Bengal region, Bangladesh should also take regional cooperation initiative for MSP.

19. 'Marine spatial planning for Bangladesh: a critical analysis of the legal and institutional regimes'. 


\subsection{Book reviews}

There are two reviews of important recent books in this issue of APJEL.

In the first review, Erin O'Donnell reviews the book Indigenous Rights and Water Resource Management: Not Just Another Stakeholder, by Katie O'Bryan. ${ }^{20}$ O'Donnell argues that the book provides essential context for understanding the import of new laws in the Australian State of Victoria, and the role of Aboriginal people in water management in Australia more broadly; as well as positioning the Australian experience within the international context of Indigenous rights and self-determination. According to the review author, while the focus of the book reviewed is on how the law can enable, support, and empower Indigenous people to participate in water management, it is also argued that there are significant substantive reasons underpinning why this should be a priority for water resource managers. The point is made in the book that as the consequences of historic water resource management and the impacts of climate change increasingly jeopardize the health of rivers and the people who rely on them, Australians are at last beginning to recognize the importance of learning from the oldest living cultures on the planet.

In the second review, Md Mahatab Uddin reviews the book Shipbreaking in Developing Countries: A Requiem for Environmental Justice from the Perspective of Bangladesh by Md Saiful Karim. ${ }^{21}$ It is explained that the book is an investigation of environmental justice in the context of the shipbreaking industries of developing countries, with a particular focus on the scenario that prevails in the shipbreaking industry of Bangladesh. It is explained that in addressing and analyzing the issue, the book author relies on a theory of environmental justice which is a juxtaposition of the modern concept of social justice and the ancient Indian concept of 'naya' (realized justice), adopted from the Idea of Justice of Amartya Sen. The review author explains that according to Karim environmental justice in the shipbreaking industry is far from realization, both at the national and the international plane; with the international legal regime being apparently more interested in shifting responsibility both for human rights abuses and for environmental injustice to developing countries engaged in shipbreaking. The reviewer describes the book as being 'the first of its kind in terms of its relevance in the context of environmental justice and highly polluting industries in the developing world'.

\section{COMMENT}

APJEL continues to reflect exciting developments in environmental law in the Asia Pacific region and the 13 articles in the two issues of the 2019 volume do, we trust, make a valuable contribution toward understanding both regional dynamics and particular country experiences.

The editorial team would like also to take this opportunity to thank the anonymous reviewers on whose time we have imposed, and on whose expertise we have drawn, to assess the articles in this and previous issues. While we cannot thank them in print by

20. Katie O'Bryan, Indigenous Rights and Water Resource Management: Not Just Another Stakeholder (Routledge, 2018) 272 pp.

21. Md Saiful Karim, Shipbreaking in Developing Countries: A Requiem for Environmental Justice from the Perspective of Bangladesh (Routledge, 2018) $150 \mathrm{pp}$. 
name, we would like to acknowledge that their input has strengthened significantly the scholarship contained in this volume, and we are deeply grateful - in a real sense, we believe that every article we publish represents a four-party relationship between authors, editors, publishers, and anonymous reviewers which is too often under-recognized.

Ed Couzens and Tim Stephens

Editors

Assisted on this issue by

Evan Hamman

Faculty of Law, Queensland University of Technology

Cameron Holley

Faculty of Law, University of New South Wales

Saiful Karim

Faculty of Law, Queensland University of Technology

Kate Owens

The University of Sydney Law School

Manuel Solis

The University of Adelaide Law School 